\title{
Sirkka Knuuttila
}

\section{Friederike Mayröcker - kun kuolema ja muusat ilmestyvät}

Nuorena naisena olin jo hyvin herkkä kaikelle eroottiselle, rakastuin tuhat kertaa. Kaikki oli siinä. Mutta kuoleman ja muusien ilmestyttyä Ernst [Jandl] ja minä halusimme kulkea yhdessä kaiken läpi. (Ks. Radisch 2004.)

Itävallan nykyhetken runoilijoista tunnetuin ja tunnustetuin, Friederike Mayröcker (s. 1924), täytti 80 vuotta joulukuussa 2004. Mayröcker kuuluu Ingeborg Bachmannin ja Elfriede Jelinekin ohella niiden kolmen naiskirjailijan joukkoon, jotka ovat ratkaisevalla tavalla luoneet saksankielisen naiskirjallisuuden historiaa 1900-luvun Wienissä. Hänen laaja tuotantonsa koostuu pääosin lyriikasta ja kokeellisesta proosasta, mutta se sisältää myös lastenkirjallisuutta, näytelmiä ja kuunnelmia. Pitkän linjan avantgardistina Mayröcker on jatkuvasti testannut kielen rajoja ja tuottanut niin modernia keskuslyriikkaa, dadaistista leikittelyä kuin poliittis-yhteiskunnallista satiiria. Hänen viime vuosien lyriikkansa käsittää väkevää ja aistivoimaista urbaania luonnonrunoutta, jota sävyttävät menetyksen tunnot ja kuoleman läheisyys.

Mayröcker syntyi Wienissä ja kasvoi äitinsä hoivissa jäätyään muutaman kuukauden iässä isästään orvoksi. 11-vuotiaaksi asti hän vietti kesänsä isovanhempiensa luona pienessä Deinzendorfin kylässä Weinviertelissä ja sai siten kosketuksen luontoon. Uppoaminen mielikuvitusmaailmoihin säästi hänet nuorena kokemasta sodan väkivaltaisuuksia Wienin kaduilla. Sodan aikana 1940-luvun alussa hän toimi lennonjohdon alaisuudessa. ${ }^{2}$ Oltuaan vastentahtoisesti englannin kielen opettajana vuosina 19461969 Mayröcker antautui vapaaksi kirjailijaksi. Hän osallistui "Wiener Gruppen" toimintaan, johon kuuluivat mm. Gerhard Rühm, H. C. Artmann ja Andreas Okopenko. Ratkaisevaksi muodostui kuitenkin hänen vuonna 1954 alkanut ystävyytensä ja yhteistyönsä kirjailija Ernst Jandlin kanssa. Elämänkumppanuus jatkui 46 vuotta aina Jandlin kuolemaan saakka. Vaikka yhteiselämän pohjana olikin henkinen sukulaisuus, taiteilijapari asui saman rakennuksen eri asunnoissa. Die Zeit -lehdelle antamassaan 80-vuotishaastattelussa Mayröcker sanoo onnistuneen rakkaussuhteensa perustuneen partnerin hyviin ominaisuuksiin: toisaalta Jandl oli suorasukaisen avoin luovan työn kysymyksissä, toisaalta hänen luotettavuutensa loi turvallisuudentunnetta, jonka ansiosta kumpikin kirjailija saattoi toteuttaa itsenäisesti omaa uraansa (Radisch 2004).

\section{Laaja ja palkittu tuotanto}

Mayröckerin tuotanto käsittää yli 80 nimikettä, ja hänelle on myönnetty miltei kaikki saksalaisen kielialueen tärkeimmät huomionosoitukset ja palkinnot. ${ }^{3} 1950$-luvulla hän 
in tuhat irnst [Jandl] . $)^{1}$

ke Mayröcker (s. org Bachmannin jotka ovat ratkai-luvun Wienissä. coosasta, mutta se jan avantgardistimodernia keskusria. Hänen viime conrunoutta, jota dutaman kuukauhempiensa luona en luontoon. Upsodan väkivaltaimi lennonjohdon a vuosina $1946-$ ner Gruppen" toiAndreas Okopenut ystävyytensä ja kui 46 vuotta aina kinen sukulaisuus, idelle antamassaan eensa perustuneen avoin luovan työn nnetta, jonka ansiRadisch 2004).

inetty miltei kaikki ${ }^{3} 1950$-luvulla hän kirjoitti modernia keskuslyriikkaa ja luotti tavallisen kielen kykyyn ilmaista emotionaalisia tiloja. 1960-luvun alussa perinteinen tyyli osoittautui ahtaaksi. Seurasi vapauttava murros: Mayröcker alkoi kursailematta yhdistellä kaiken vastaansa tulevan arkisen ja populaarin tekstiaineksen (ks. Lindemann 1979). Montaasitekniikoilla syntyneitä groteskeja runokollaaseja leimasi radikaali parodinen vire, ja niitä säestivät joskus yksinkertaisen vitsikkäät piirrokset. Jandl aloitti samoihin aikoihin äänirunoutensa, joten ei olekaan ihme, että parin yhteistyönä syntyneet, musiikkia ja hälyääniä monipuolisesti hyödyntävät kuunnelmat palkittiin juuri melodisuutensa ansiosta. Kuvaava esimerkki Mayröckerin tämän kauden lyriikasta on kokoelma Tod durch Musen (1966). Tekstien mattomainen kudos perustuu yhä enemmän dialogisuuteen: Mayröcker ei kirjoita mistään aiheesta ylhäältä käsin, über, vaan aina horisontaalisti joko durch eli jonkin läpi tai mit, jonkin kanssa, kuten osoittavat runojen otsikot "Text mit den langen Bäumen des Webstuhls", "Text mit William Blake", "Text mit Steinen" ja "Text mit Erdteilen" tai "Text 'bei mozambique" ja "Text dem Mazedonischen angenähert" (Lindemann 1979, 9). Kuten jo näistä otsikoista käy ilmi, Mayröckerin tuotannolle ominaisia piirteitä ovat laajat aihepiirit ja intertekstuaalisuus.

1970-luvulla Mayröcker siirtyi kirjoittamaan etupäässä proosaa, kuunnelmia ja näyttämötekstejä. Romaaneista mainittakoon Je ein umwölkter Gipfel (1973) ja Das Licht in der Landschaft (1975). Molemmat edustavat Mayröckerille tyypillistä tajunnanvirtatyyliä, jota hän sittemmin on kehittänyt ja monipuolistanut. Edellisen romaanin kerronta perustuu vuorottelulle "hän sanoi" - "me sanoimme" (sagte er - sagte sie - sagten wir), kun taas jälkimmäisessä minäkertojan muisti- ja mielikuvien vaihtelu sulattaa nykyisen ja menneen yhteen kertomukseksi mielen draamasta. 1980- ja 1990-luvun kokeelliset proosateokset muuntelevat samaa mattomaista tekniikkaa ja huipentuvat intertekstuaaliseen romaaniin brütt oder Die seufzenden Gärten (1998) (ks. Winkler 2004). Omien sanojensa mukaan Mayröcker saavutti kirjoittaessaan brüttiä (saksannos ranskan sanasta brut, 'raaka', 'tunnoton') vihdoinkin täyden piittaamattomuuden sekä itsensä että kirjallisen maailman rajoituksista, elämyksen, josta hän yhä luovana tilana unelmoi (Radisch 2004). Lisäksi brütt merkitsi paluuta elinvoimaiseen lyriikkaan, jota oli ennakoinut kokoelma Notitz auf einem Kamel (1996). Valaisevan katsauksen Mayröckerin taiteelliseen ajatteluun tarjoaa proosarunoa ja vapaamuotoisia esseitä sisältävä Magische Blätter IV vuosilta 1983-2001, varsinkin kun sen sisältämät tekstit tuskin antautuvat mainituille geneerisille luokituksille. ${ }^{4}$

Jandlin kuoltua vuonna 2000 syntyi proosateos Requiem für Ernst Jandl (2001), surun ja valituksen kirja. Siinä kuolleen kumppanin kanssa käydyt keskustelut kietoutuvat sisäisiin pohdiskeluihin ja ulkomaailmasta tunkeutuviin ääniin. Uusimman lyriikan arjesta ja luonnosta purkautuvien elämysten osin elegiset piirteet löytyvät runoteoksista Mein Arbeitstirol (2003) ja Die kommunizierenden Gefässe (2003). Runoi- 
lijan 80-vuotispäiväksi julkaistiin yli tuhat runoa sisältävä teos Gesammelte Gedichte 1939-2003 (2004). Syksyllä 2005 tästä mammuttiopuksesta ilmestyi jo kolmas painos, samalla kun markkinoille tuli Jandlin muistoksi kirjoitettu romaani Und ich schüttelte einen liebling.

80-vuotisjuhlassaan Mayröcker sai harvinaisen lahjan. Hänen runonsa "was brauchst du" ("mitä tarvitset") vuodelta 1995 käännettiin noin 150 kielelle eri puolilla maailmaa. ${ }^{5}$ Kääntäjien itse käsin kirjoittamat lehdet sidottiin kirjaksi. Tässä uniikissa teoksessa on suoranaisia kalligrafisia aarteita ja kiehtovin käsialoin kirjoitettuja tekstejä, jotka edustavat sekä tuttuja että vieraita, suuria ja pieniä kieliä ja murteita kaikista maanosista, kertoo käännösten kokoajana toiminut Christel Fallenstein. Sana on kulkenut maasta toiseen, ja käännöksiä lähetetään vieläkin Wieniin. Syyskuussa 2005 saapui mm. tieto Afrikasta zulun- ja xhosankielellä valmistuvista versioista. Innostus sai alkunsa siitä, että "was brauchst du" kuuluu eräänlaisena hiljaisena julistuksena Mayröckerin jokaiseen lukutilaisuuteen, Lesungiin, joita hän pitää edelleen tiuhaan tahtiin ympäri Eurooppaa.

\section{Monen tyylin taituri}

Kun runoilijan ura on pitkä ja vaiheikas, on mahdollista esitellä vain pieni tyyliotos koko laajasta repertoaarista. Mayröckerin taiteen tärkein ja pysyvin ominaispiirre on kuitenkin nimettävissä: taipumus kokea ja löytää kieli yhä uudelleen uusia mentaalisia hahmoja synnyttävänä välineenä. Lauseella "Ich sehne mich nach meinen ungeschriebenen Werken" (kaipaan kirjoittamattomia teoksiani) Mayröcker painottaa kirjoituksensa olevan orgaaninen osa elämän jatkuvuutta. Toisin kuin Jelinek hän ei usko kielen olevan merkityksen antajana tuhoutunut, kaputt, vaan hän luottaa satunnaisen henkilökohtaisen elämyksen kieleksi muuntuvaan voimaan. (Radisch 2004.) Yleisöä viehättääkin juuri runoilijan kielen autenttisuus ja kiihkeä tempo. Nämä ominaisuudet vetävät puoleensa myös puolta nuorempia, keskieurooppalaiseen hybrikseen turhautuneita runoilijoita, kuten Mayröckerin vankkumattomiin ihailijoihin kuulunut runoilija Thomas Kling (2001) on todennut. Siksi tähän esittelyyn suomentamani esimerkkirunot edustavat Mayröckerin 2000-luvun tyyliä, nimenomaan sitä ruumiillisuuteen juurtunutta autenttisuutta, jonka kaikupohjana on ihmisen kuolevaisuus.

Mayröcker ilmoitti jo 1970-luvulla pyrkimyksekseen ilmaista eriaikaisten ilmiöiden (Vorgang) samanaikaisuutta ihmismielessä (Lindemann 1979, 9, 16). ${ }^{6}$ Tätä vaatimattomalta kuulostavaa mutta vaativaa päivittäistä päämäärää kuvaa ehkä parhaiten Tomas Tranströmerin käsite sanningsbarriär (totuudenkynnys): se paikka, jossa sisäisen ja ulkoisen maailman kohdatessa "kirjoitus tulee näkyväksi" (Westerberg 1996, 77). Eriaikaisten ilmiöiden kielellinen fuusio ei kuitenkaan Mayröckerillä johda aforistiseen tyyneyteen tai sovintoon. Hänen sisäinen seismografinsa rekisteröi arkipäivän impuls- 
melte Gedichte kolmas painos, id ich schüttelte runonsa "was lelle eri puolilla Tässä uniikissa oitettuja tekstemurteita kaikisnstein. Sana on yyskuussa 2005 sta. Innostus sai listuksena Maytiuhaan tahtiin

n pieni tyyliotos ominaispiirre on uusia mentaalisia inen ungeschrieinottaa kirjoitukän ei usko kielen satunnaisen hen004.) Yleisöä viemä ominaisuudet rikseen turhautukuulunut runointamani esimerki ruumiillisuuteen isuus. riaikaisten ilmiöi$9,16) .{ }^{6}$ Tätä vaaraa ehkä parhaiten ikka, jossa sisäisen terberg 1996, 77). i johda aforistiseen arkipäivän impuls- sivirtaa tietoisen ja esitietoisen kynnyksellä niin, että fyysisten aistimusten ja assosioivan kielen välinen affektilataus purkautuu sarjallisesti kuvasta toiseen. Itseään vastaan protestoiva kieli tuntuu kantavan kirjoittamisen vimmaa niin kauan, että sisäisen tai ulkoisen riittävä synteesi on saavutettu.

Mayröckerin 1960-luvun alussa kokeman tyylillisen käänteen vaikutus ulottuu uusimpiin runoihin asti. Montaasitekniikka muokkasi kirjoittajastaan intertekstuaalisuuden taiturin. Tuloksena on kaiun tavoin etenevää, visuaalisia havaintoja, tuntemuksia ja faktuaalisia elementtejä metaforiksi muuntavaa ajatusten virtaa (ks. Hell 1985, 239; vrt. Lehtonen 1981). Mayröckerin runouden tunnusmerkkejä ovat kaksoismerkityksiä tuottava säkeenylitys, ketjuuntuva melodinen allitteraatio, neologismit sekä assosiaatioille ja lipsahduksille perustuva luettelomaisuus, jotka tuottavat yhteismitattomia elämyksiä ja merkityksiä. Silloittavina elementteinä ovat sitaatit, huudahdukset ja sidesanat, kuten rytmisesti toistuvat ja- tai koska-sanat sekä puheenomaiset luulen- tai erityisen tyypillinen nimittäin-sana. Typografisiksi keinoiksi ovat vähitellen vakiintuneet kaksoispiste ja toisistaan erillään oleva pistepari, sitaattien kursivointi sekä tärkeiden asioiden korostus mit Kapitällchen eli pienten kirjainten kokoisin versaalein. Samoin saksan epämääräisen artikkelin sijasta käytetty numero 1 on omiaan nostamaan esiin jonkin yksittäisen asian ilmiöiden luettelossa. Erikoisuutena on säilynyt saksan kaksoiss-kirjaimen kirjoittaminen kirjaimilla sz, mikä juontaa Mayröckerin ensimmäisestä kirjoituskoneesta, jossa ß-merkkiä ei ollut.

\section{Ajatuslepatuksesta aivoihmeeseen}

Mayröcker tunnustaa olevansa Lumpensammlerin, roskisdyykkari, joka työstää keräämänsä mielenkiintoiset jätteet kääntämällä ne nurin. Hän on saanut virikkeitä muun muassa sellaisilta kirjailijoilta kuin Beckett, Derrida, Musil, Barthes, Duras ja Bataille, vain muutamia mainitakseni. Toinen ehdoton innoituksen lähde on musiikki, kuten Maria Callasin laulut tai Bachin kantaatit. ${ }^{7}$ Nuoruusvuosien jälkeen Mayröckerin käsitys runouden tehtävästä on sekin kääntynyt ympäri. Hän sanoo uskoneensa maksiimiin "Kauneus on totuus", mutta nykyisin hän sanoo mieluummin "Totuus on kauneus." (Radisch 2004.) Näin hän ilmaisee hakeutuvansa lähelle sitä, mitä simulacrumien maailmasta ei enää tahdo löytyä. Mikään yksittäinen kohde ei ole itsessään kaunis, vaan sen luonne näyttäytyy nopeassa kaksoisvalaistuksessa, esim. kun Itävalta koetaan ja kirjoitetaan Italian läpi tai kasvillisuus ja luonnonelementit lapsuuden elämysten läpi (vrt. Kling 2001). Runoilija nimittää tätä intuitiivista metodiaan termeillä Denkflattern (ajatuslepatus), Schädelfreude (päkoppariemu) ja Gehirnwunder (aivoihme). Yksityisestä aisti- ja ajatusnautinnosta on muokkautunut maailmaan suuntautuva, lukijan ajattelun pohjia hämmentävä instrumentti.

Poimiessani näytteitä oheiseen valikoimaan runoilijan 2000-luvun tuotannosta 
olen keskittynyt runoihin, joita Mayröcker useimmin on lukenut esiintyessään. ${ }^{8}$ Runoista vain ensimmäinen on kymmenen vuoden takaa; muut saavat olennaisen sävynsä Jandlin kuolemasta, siihen liittyvästä menetyksestä ja täydeksi eletystä rakkaudesta. Samalla kun ne paljastavat syvän kaipauksen, ne kirjaavat kuoleman läheisyyttä elämän aistillisen rikkauden rinnalla. Äkillisen menetyksen aiheuttama shokki, muistikuvat rakastetusta ja kuolevan sulautuminen luontoon ovat purkautuneet rajuiksi ja sensitiivisiksi kuviksi.

Mayröcker selvittää 80-vuotishaastattelussaan suhdettaan kuolemaan: "Vihaan kuolemaa. Tiedän olevani pian sen ovella. En voi verrata sitä mihinkään, se on kuristava kuvitelma. - Se on käsittämätöntä. Vääryys! Ihminen haluaisi toki tietää miten maailman käy. Hän tulee leikatuksi pois saamatta tietää, jatkuuko kaikki, miten se jatkuu. Se on yksinkertaisesti poissa laskuista." Samalla hän tunnustaa rakkautensa elämään ja myötätuntonsa syrjäytyneitä kohtaan: "Olen yhä uteliaampi elämää kohtaan. Haluaisin elää vielä vähän, päästä perille monista asioista. On katsottava pieniä asioita. - Minua liikuttaa [osattomien ihmisten tila] niin, että voisin ulvoa kadulla." (Radisch 2004.)

Seuraava valikoima antaa kuvan Mayröckerin maailman "vihreästä rehevästä kauneudesta", jota "was brauchst du" -runo peräänkuuluttaa. Teksteissä mielentilat ja arjen esineet risteytyvät vapaana virtailevaan luontoon urbaanien näkyjen keskellä. Ne purkautuvat ajoittain hyökymäisesti eteneväksi liikkeeksi, jossa on katkeilevan hengityksen rytmi. Vuosikymmenten takaa ilmestyvät Deinzendorfin kylän maagiset figuurit, kuten lapsuuden myrkyllinen sudenmaito, höyhenpilvet ja sembrat (zirren, zirben), koiranheisipuu, magnoliat, kukkien runsaus, mielikukat (valkoiset liljat), kaiken yllä taivaan juhlakatos ja kotiin palaavat pääskyset. Sanojen sointi (Klang) on runoilijalle käännöksessäkin tärkeämpi kuin tarkka merkitys, sillä hän olettaa soinnin ja rytmin herättävän lukijan omat fyysiset tuntemukset ja assosiaatiot. ${ }^{9}$ Sarja noudattaa luonnollista kronologiaa, sillä päivämäärät ja omistuskirjoitukset ovat Mayröckerille nykyisin hyvin tärkeitä.

\section{Viitteet}

${ }^{1}$ „Als junge Frau war ich schon sehr empfänglich für alle erotischen Dinge, ich habe mich tausendmal verliebt. Es war alles da. Aber mit dem Erscheinen von Tod und Musen, wollten Ernst und ich aufs Ganze gehen." (Ks. Radisch 2004.)

${ }^{2}$ Lapsuudesta ja sota-ajasta Mayröckerin taiteeseen vaikuttavina tekijöinä saa käsityksen esim. Magische Blätter -teoksen luvusta „Durchschaubild Welt, Versuch einer Selbstbeschreibung“" (s. 188-194).

${ }^{3}$ Lukuisista palkinnoista mainitrakoon Saksan sotasokeiden kuunnelmapalkinto 1969 (Ernst Jandlin kanssa tehdyistä kuunnelmista), Itävallan kirjallisuuden valtionpalkinto 1974, lyriikan Georg Trakl -palkinto 1977, Itävallan valtionpalkinto 1982, Roswitha von Gandersheim -palkinto 1982, Friedrich Hölderlin -palkinto 1993, Else Lasker-Schüler -palkinto 1996, 
intyessään. ${ }^{8} \mathrm{Ru}-$ ennaisen sävynsä rakkaudesta. Saheisyyttä elämän kki, muistikuvat rajuiksi ja sensi-

emaan: "Vihaan xään, se on kuristoki tietää miten kaikki, miten se a rakkautensa eläi elämää kohtaan. ava pieniä asioita. radulla." (Radisch stä rehevästä kaunielentilat ja arjen keskellä. Ne purzeilevan hengitykmaagiset figuurit, at (zirren, zirben), liljat), kaiken yllä ng) on runoilijalle soinnin ja rytmin oudattaa luonnolröckerille nykyisin

, ich habe mich id Musen, wollten saa käsityksen esim. lbstbeschreibung"

Ikinto 1969 (Ernst kinto 1974, lyriikan 1 Gandersheim palkinto 1996,
Droste -palkinto ja America Awards -palkinto 1997, Christian Wagner -palkinto 2000, Georg Büchner -palkinto 2001. (Ks. muut palkinnot, arvonimet ja jäsenyyder Lyrikwelt 2005.) ${ }^{4}$ Mayröckerin työskentelytapa käy hyvin ilmi Marcel Beyerin tekemästä haastattelusta (Beyer 1988/1994).

${ }^{5}$ Runo on julkaistu suomeksi Stefan Mosterin (2005) toimittamassa saksankielisen kirjallisuuden antologiassa Puiden lobtu Anni Sumarin käännö̈ssenä. Lahjakirjaan suomentamani versio jlmestyi kolmentoista muun käännöksen joukossa kirjallisuuslehdessä KONZEPTE. Zeitschriff fur Literatur $(2005,53)$. Lehdessä mainitaan, että kaikki noin 150 käännöstä ovat esillä Münchenin Lyrikkabinettin näyttelyssä.

${ }^{6}$ Mayröckerin määritelmä korostaa kirjoittajan ja muiden ihmisten sisäisten kokemusten samanaikaisuuttạ. Se kuuluu: „die Gleichzeitigkeit von Vorgängen, von inneren Vorgängen also, die man gleichzeitig hat, mit allen möglichen Menschen gleichzeitig und mit sich selbst gleichzeitig auf verschiedenen Ebenen." ("Tapahtumien samanaikaisuus, siis sisäisten tapahtumien, joita ihmisellä on yhtaikaa yhdessä kaikkien mahdollisten ihmisten kanssa ja itsen kanssa yhtaikaa eri tasoilla.") Ks. romaanin Fast ein Frühling des Markus M. (1976) etulieve.

${ }^{7}$ Esim. brïttiä kirjoittaessaan Mayröcker kuunteli muuatta Bachin kantaattia yhä uudelleen (Radisch 2004). Romaanin Heiligenanstalt (1978) aineksena ovat säveltäjien elämäkerrat, kirjeet ja heidän musiikkinsa. Teoksessa esiintyvät Frédéric Chopin, Robert ja Clara Schumann, Johannes Brahms, Anton Bruckner ja Franz Schubert. Lopussa on luetrelo musiikkikappaleista, joilla kirjailija stimuloi itseään teosta kirjoittaessaan.

${ }^{8}$ Kiitokset Gabriele Schrey-Vasaralle ja Rauni Paalaselle korjauksista ja ehdotuksista suomennosten viimeistelyssä.

${ }^{9}$ Suomennosten muotoon ja sanavalintoihin ovat vaikuttaneet Friederike Mayröckerin kanssa Christel Fallensteinin välityksellä käymäni keskustelut.

\section{Lähteet}

\section{Friederike Mayröckerin teokset}

Tod durch Musen. Poetische Texte (1966). Hamburg: Rohwolt Reinbek. Je ein umwölkter Gipfel. Roman (1973). Frankfurt am Main: Suhrkamp. Das Licht in der Landschaft. Roman (1975). Frankfurt am Main: Suhrkamp. Fast ein Frühling des Markus M. Roman (1976). Frankfurt am Main: Suhrkamp. Heiligenanstalt. Roman (1978). Frankfurt am Main: Suhrkamp. Notiz aufeinem Kamel. Neue Gedichte (1996). Frankfurt am Main: Suhrkamp. brütt oder Die seufzenden Gärten. Roman (1998). Frankfurt am Main: Suhrkamp. Requiem für Ernst Jandl (2001). Frankfurt am Main: Suhrkamp. Magische Blätter I-V(2001). Frankfurt am Main: Suhrkamp. Mein Arbeitstirol. Gedichte 1996-2001 (2003). Frankfurt am Main: Suhrkamp. Die kommunizierenden Gefässe (2003). Frankfurt am Main: Suhrkamp. Und ich schüttelte einen liebling. Roman (2005). Frankfurt am Main: Suhrkamp. Gesammelte Gedichte 1939-2003 (2005). Toim. Marcel Beyer. 3. painos. Frankfurt am Main: Suhtkamp. 
was brauchst du. Das literarische Bonbon. KONZEEPTE. Zeitschrift für Literatur 25/2005, s. 53-61.

\section{Haastattelut}

HELL, BODO 200I/I985: es ist so ein Feuerrad. Bodo Hell im Gespräch mit Friederike Mayröcker in deren Wiener Arbeitszimmer am 28. September 1985. Friederike Mayröcker: Magische Blätter IV. Frankfurt am Main: Suhrkamp, s. 232-252.

BEYER, MARCEL 1994/I988: Eigentlich ist es nichts anderes als ein poetischer Synthesizer. Marcel Beyer im Gespräch mit Friederike Mayröcker am 28. März 1988 in Wien. Zwischen den Zeilen. Eine Zeitschrift für Gedichte und Ihre Poetik. August 1994, Heft 4. Basel und Weil am Rhein: Verlag Urs Engeler, s. 64-81. [Saatavilla myös www-muodossa <URL: http://www.engeler.de/beyermayroecker.html>, 12.2.2006.]

RADISCH, IRIS 2004: Die Welt ist so reich. Zum Geburtstag der grossen Wiener Dichterin Friederike Mayröcker: Ein Gespräch über die Unbegreiflichkeit des Lebens. Die Zeit 52/2004. Saatavilla www-muodossa <URL: http://www.zeit.de/2004/52/LMayr_9acker>, 12.2.2006.

\section{Julkaisemattomat haastattelut}

Sirkka Knuuttilan keskustelut Friederike Mayröckerin kanssa Christel Fallensteinin välityksellä sähköpostitse heinäkuusta 2002 marraskuuhun 2005.

\section{Muu kirjallisuus}

KLING, THOMAS 200I/I 997: ja es ist wieder Frühling, aberŠ. Über Friederike Mayröckers unermüdliche Fortsetzung sprachlicher Versuchsanordnungen. Friederike Mayröcker Ein städtischer Kontinent in doppelt belichteten Bildern. Die goldgelbe Früchte gesichtet. Literaturlandschaft Österreich. Saatavilla www-muodossa <URL: http://webmail.horus.at/pipermail/biblio-forum/2001/000122.html>, 18.12.2005.

Lehtonen, Maija I98I: Naisia ja haltiattaria. Parnasso 2/1981, s. 100-104.

LINDEMANN, GISELA 1979: Das Licht am Ende des Tunnels. Versuch über das Werk der Friederike Mayröcker. Friederike Mayröcker. Ein Lesebuch. Toim. Gisela Lindemann. Frankfurt am Main: Suhrkamp, s. 7-17.

LYRIKWELT 2005: <URL: http://www.lyrikwelt.de/autoren/mayroecker.htm>,

18.12.2005

mOSter, stefan 2005: Puiden lohtu. Saksankielistä runoutta 1946-2000. Helsinki: WSOY.

WESTERBERG, CAJ I 996: Suomentajan jälkilause. Tomas Tranströmer: Totuudenkynnys. Surugondoli. Kaksi runokokoelmad. Helsinki: Tammi, s. 77-78.

WINkLER, ANDrea 2004: Schatten(spiele); Poetologische Denkwege zu Friederike Mayröcker. Poetica - Schriften zur Literaturwissenschaft, Band 74. Hamburg: Verlag Dr. Kovaè. 